\title{
The significance of physical education in American schools
}

\begin{abstract}
Many children in America do not receive the needed amount of physical activity needed to maintain a healthy weight. Literature describes the health benefits related to daily physical education and activity. Physical education programs are used as a strategy to prevent obesity and to promote overall health. The majority of American schools do not provide daily physical education. It is recommended that children have 30 minutes of physical education and a total of 60 minutes of activity every day.
\end{abstract}

Keywords: physical education, physical activity, obesity, overweight, daily activity
Volume 4 Issue I - 2017

\author{
Hommes Tiffany J \\ Department of Nursing, Bemidji State University, USA
}

Correspondence: Hommes, Tiffany J, Bemidji State University, Department of Nursing, Bemidji State University, USA,

Email thommes@bemidjistate.edu

Received: September 21, 2017 | Published: October 16, 2017

\section{Introduction}

Many children in America do not receive the needed amount of physical activity needed to maintain a healthy weight. Approximately $17 \%$ of children are obese ${ }^{1}$ and one in three children are overweight or obese. ${ }^{2}$ This is a local and national emergency that needs to be addressed to keep children healthy, prevent morbidities, and control the costs associated with being overweight or obese. Pre-diabetes, type 2 diabetes, and hypertension in children is at an all time high. However, data indicates that only 3.8 percent of American elementary schools provide daily physical education. ${ }^{3}$ This paper will discuss the importance of daily physical education in American schools.

There is an abundance of support to provide daily physical education in our schools. Previous First Lady Michelle Obama led a national initiative called "Let's Move" to reverse the childhood obesity epidemic. One of the initiatives in "Let's Move" is to increase physical activity. ${ }^{4}$ In fact, Healthy People 2020 has objectives to increase the portion of America's private and public schools that require daily physical education. ${ }^{5}$ There is also a national initiative, the FIT Kids Act of 2015-2016, ${ }^{6}$ that provides for increasing quality and quantity of physical education in America's schools.

\section{Benefits of daily physical education}

Physical Education is a formal course based on sequential learning focused on activity that is taught by a licensed professional. ${ }^{7}$ There is an abundant amount of evidence and research favoring daily physical activity for children to improve physiologic health status. First, physical education programs are used as a strategy to prevent disease and obesity. Research shows that children who engage in daily physical education are more likely later in life to continue physical activity as an adult. ${ }^{8}$ Physical education programs in the schools can reduce the incidence of overweight children. ${ }^{9}$ As the amount of physical activity increases, students' aerobic and physical fitness increases. Exercise improves muscle, bone, and joint health. Exercise also modifies diabetes risk factors. Studies show regular exercise can restore blood vessel function and improve cardiovascular risk factors in obese children. ${ }^{10}$

Many studies have found that regular participation in physical activity during the school day enhances cognition. Daily physical activity actually increases grades/scores on standardized tests. Even though these students have less instructional time, scores improve. ${ }^{3}$
There is also evidence that activity breaks can improve cognitive performance and classroom behavior. Providing daily activity has been shown to increase concentration, and decrease fidgeting in the classroom. ${ }^{11}$ Finally, a high quality physical education program can enhance social/emotional development in children. ${ }^{12}$ Physical activity also has a positive impact on insomnia, tobacco use, depression, and anxiety. ${ }^{13}$ There is also less absenteeism in normal weight children. ${ }^{14}$ The list of benefits for daily physical education and physical activity is so massive, it is difficult to quantify in one article.

\section{Support for daily physical education}

Fortunately, with mounds of research available to support daily, quality, physical education of at least 30 minutes, and physical activity of 60 minutes a day, many interest groups support physical education. National interest groups including the American Academy of Pediatrics, American Heart Association, United States Department of Health and Human Services, United States Department of Education, and National Association for Sport and Physical Education, the President's Council on Physical Fitness and the Centers for Disease Control are supportive of quality physical education in schools. ${ }^{8}$ As specially trained experts in physical activity, physical education teachers realize the importance of daily physical activity. Parents are also supporters of daily physical education. Ninety-five percent of parents think that daily physical activity "should be part of a school curriculum for all students in grades K-12". "The next group to support this effort is teachers from all disciplines. Eighty-six percent of teachers report agreeing that students in all grade levels should participate in physical education lasting at least 30 minutes. ${ }^{15}$

\section{Conclusion}

In this article, evidence was provided to describe the importance of quality, daily, physical education in American schools. There are numerous benefits to daily physical education including paving the way for a lifetime of fitness. Physical education is a worthy intervention to increase activity levels for children.

\section{Acknowledgements}

None.

\section{Conflict of interest}

The author declares no conflict of interest. 


\section{References}

1. The robert wood johnson foundation. Declining childhood obesity rates; 2016.

2. American heart association. Overweight in children; 2016.

3. The robert wood johnson foundation. Active living research: Active education; 2007.

4. Let's Move!

5. U.S. Department of health and human services. Healthy people 2020: 2020 topics and objectives; 2011.

6. FIT Kids Act of 2015-2016, H.R. 2013.

7. Minnesota department of health. Importance of school physical education; 2008.

8. National association for sport and physical education \& American heart association. 2010 Shape of the nation report: Status of physical education in the USA. Reston VA, National Association for Sport and Physical Education; 2010.
9. National institute for health care management. Obesity in young children: Impact and intervention; 2004.

10. Kienast W, Kundt G, Lenschow U, et al. Improvement of early vascular changes and cardiovascular risk factors in obese children after a sixmonth exercise program. J Am Coll Cardiol. 2006;48(9):1865-1870.

11. Davies G, Dickerson C, Hoge P, et 1 . Impact of recess in classroom behavior: group effects and individual differences. The Journal of Educational Research. 1998;92(2):121-126.

12. American Heart Association. Address childhood obesity through quality physical education; 2011.

13. Kraak V, Suitor C. Adequacy of Evidence for Physical Activity Guidelines Development: Workshop Summary. Institute of Medicine, Washington DC, USA: National Academies Press; 2007.

14. American cancer society, American heart association, American diabetes association. Physical education in schools-both quality and quantity are important; 2008.

15. The robert wood johnson foundation. Healthy schools for healthy kids; 2003. 